\title{
Produção de mudas de maracujazeiro amarelo em substratos contendo resíduos vegetais
}

Geyci Aires Farias, Ana Claudia Costa, Sonia França Costa, Gleicy Aires Farias, Paulo Henrique Fernandes Pereira, Luciula Fereira Cabral Junior

Universidade do Estado de Mato Grosso - UNEMAT, MT. E-mail: geyci farias@hotmail.com

\begin{abstract}
Resumo
Um dos problemas enfrentados pelos produtores de maracujá é a dificuldade de obtenção de mudas de qualidade. Assim, o objetivo desse trabalho foi avaliar diferentes substratos contendo resíduos vegetais na produção de mudas de maracujazeiro amarelo. O delineamento experimental foi em bloco casualizados (DBC) com 10 tratamentos, 3 repetições, 10 plantas por parcelas, totalizando 300 mudas. Os tratamentos foram formulados com resíduos vegetais em mistura com solo em diferentes proporções expressas em volume/volume (v/v) e consistiram de: T1- resíduo de soja + solo (1:2); T2- resíduo de soja + solo (1:3); T3resíduo de soja + solo (1:4); T4- resíduo de algodão + solo (1:2); T5- resíduo de algodão + solo (1:3); T6resíduo de algodão + solo (1:4); T7- resíduo de cana-de-açúcar + solo (1:2); T8- resíduo de cana-de-açúcar + solo (1:3); T9- resíduo de cana-de-açúcar + solo (1:4); T10- solo (testemunha). As mudas foram obtidas através de sementes de maracujazeiro amarelo (Passiflora edulis Sims f. flavicarpa Deg.) cultivar 'FB200 Yellow Master'. As características avaliadas foram: altura, diâmetro do caule, número de folhas, massa fresca e seca do sistema radicular e da parte aérea. O substrato formulado com resíduo de cana-de-açúcar + solo (1:2) proporcionou maior crescimento das mudas de maracujazeiro, sendo recomendado para a produção de mudas de Maracujazeiro amarelo.
\end{abstract}

Palavras-chave: composto orgânico; Passiflora edulis Sims f. flavicarpa Deg.; propagação.

\section{Production of yellow passion fruit seedlings on substrates containing plant residues}

\begin{abstract}
One of the problems faced by passion fruit producers is the difficulty of obtaining quality seedlings, the substrate being an important input to ensure the satisfactory growth of the seedlings. Thus, the objective of this study was to evaluate different substrates containing plant residues in the production of yellow passion fruit seedlings. The experimental design was in a randomized block with 10 treatments, 3 replicates, 10 plants per plot, totaling 300 seedlings. The treatments were formulated with vegetal residues in mixture with soil in different proportions expressed in volume/volume $(\mathrm{v} / \mathrm{v})$ and consisted of: T1soybean residue + soil (1:2); T2- soybean residue + soil (1:3); T3- soybean residue + soil (1:4); T4- cotton residue + soil (1:2); + T5- cotton residue + soil (1:3); T6- cotton residue + soil (1:4); T7- sugarcane residue + soil (1:2); T8- sugarcane residue + soil (1:3); T9- sugarcane residue + soil (1:4); T10- soil (control). The seedlings were obtained from yellow passion fruit seeds (Passiflora edulis Sims f. flavicarpa Deg.) cultivar 'FB200 Yellow Master'. The characteristics evaluated were: height, stem diameter, number of leaves, fresh and dry mass of root and shoot. The substrate formulated with sugarcane bagasse + soil (1:2) was provided the highest growth of seedlings, being recommended for the production of Yellow passion fruit seedlings. Keywords: organic compound; Passiflora edulis Sims f. flavicarpa Deg.; propagation.
\end{abstract}




\section{Introdução}

O Brasil é o terceiro maior produtor mundial de frutas, atrás apenas da China e Índia. Juntos, esses países produzem $44,2 \%$ do total mundial e suas produções são destinadas principalmente aos seus mercados internos. A fruticultura é um dos setores de maior destaque do agronegócio brasileiro e vem conquistando resultados expressivos, gerando oportunidades de emprego e renda para pequenos e médios produtores rurais (ANUÁRIO BRASILEIRO DE FRUTICULTURA, 2015).

Nesse cenário promissor, o maracujazeiro se destaca por ser uma frutífera nativa, bem adaptada às diferentes condições edafoclimáticas do Brasil e por possuir excelente aceitação no mercado interno. A planta é do gênero Passiflora, que possui aproximadamente 400 espécies, destacando-se entre essas o maracujazeiro amarelo (Passiflora edulis Sims f. flavicarpa Deg.), responsável por $95 \%$ do plantio em pomares, devido à alta produtividade, vigor e qualidade dos frutos (MELETTI, 2011).

Um dos problemas enfrentados pelos produtores de maracujá é a dificuldade na obtenção de mudas de qualidade que podem garantir o sucesso do pomar. Isso vem levando a utilização de sementes de plantios anteriores de espécies não melhoradas, o que pode gerar baixa produtividade dos pomares.

No sistema atual de produção de mudas de maracujazeiro a utilização de substratos adequados e a complementação com fertilizantes apresentam como vantagens 0 bom desenvolvimento do sistema radicular e a redução do tempo para a formação das mudas (ALMEIDA et al., 2014). Mudas de boa qualidade podem apresentar melhor adaptação no campo, dispensando, assim, o replantio, e reduzindo a mão-de-obra na manutenção do pomar, além de proporcionarem maior produtividade.

Para a produção de mudas de alta qualidade é importante a utilização de substratos que apresentem propriedades físico-químicas adequadas e que forneçam os nutrientes necessários para o desenvolvimento da planta. Os substratos devem apresentar ausência de patógenos, baixa densidade, composição química equilibrada, boa coesão entre as partículas e aderência junto às raízes (RAMOS et al., 2002). Assim, a produção de mudas com alta qualidade e preço acessível ao produtor, depende do sistema utilizado para sua produção com a utilização de insumos de baixo custo (ALMEIDA et al., 2014), a exemplo de resíduos agrícolas.

Vários compostos provenientes de atividades agrícolas estão sendo estudados para se verificar a possibilidade de utilização dessas fontes renováveis como alternativa promissora para a geração da denominada bioenergia, em substituição pelo menos parcial de combustíveis de origem fóssil e não renovável (SOARES et al., 2015). Outra alternativa de utilização desses resíduos vegetais seria na composição de substratos para o cultivo de espécies vegetais, podendo-se realizar a mistura destes compostos com solo para se obter melhores condições químicas e físicas do substrato, proporcionando maior crescimento das plantas (SERRANO et al., 2006).

Costa et al. (2007) destacam a importância da utilização de matérias primas regionais, como casca de arroz, bagaço de cana-de-açúcar, casca de pinus, lixo urbano, resíduo da produção de papel, fibra de coco e resíduo de algodão proveniente do processamento da indústria têxtil, visando seu aproveitamento em outras atividades. No entanto, pesquisas com reutilização de resíduos vegetais ainda são incipientes (CALDEIRA et al., 2008).

Nos últimos anos, a crescente pressão ambientalista tem levado as indústrias a buscarem destinos alternativos para os resíduos dos seus processos industriais, no mesmo sentido, os resíduos agrícolas têm se tornado um grande problema de ordem social e ambiental, necessitando-se de alternativas para sua correta destinação (SILVA et al., 2014). Assim, os resíduos provenientes da agricultura causam preocupação, devido às restrições de espaço para acomodação, riscos de contaminação ambiental e a necessidade de se proporcionar um destino final a eles (TORRES et al., 2012).

Há a necessidade de se desenvolver pesquisas sobre a reutilização de resíduos agropecuários visando seu aproveitamento dentro de processos produtivos na própria cadeia de produção ou em outras. Apesar dessa demanda, são poucos os estudos conduzidos no Brasil, principalmente sobre a utilização de resíduos provenientes das atividades de produção de algodão, cana-deaçúcar e soja. Assim, a utilização de substratos contendo resíduos vegetais pode ser uma alternativa viável de reaproveitamento desses materiais (CALDEIRA et al., 2008). 
Objetivou-se com esse trabalho avaliar a produção de mudas de maracujazeiro amarelo em substratos contendo resíduos vegetais.

\section{Material e Métodos}

$O$ experimento foi realizado na Universidade do Estado de Mato Grosso (UNEMAT), no Campus de Nova Xavantina-MT. O município está localizado nas coordenadas $14^{\circ} 41^{\prime} 09^{\prime \prime} \mathrm{SE}$, $52^{\circ} 20^{\prime} 09^{\prime \prime} \mathrm{W}$, com altitude média de $275 \mathrm{~m}$. O clima da região é do tipo Aw, segundo a classificação do Köppen, possuindo duas estações bem definidas, uma seca que vai de abril a setembro e outra chuvosa, que vai de outubro a março, com precipitação pluviométrica de 1600 $\mathrm{mm}$ anuais. A temperatura média, umidade relativa média e precipitação para o período de execução do experimento (7 de novembro de 2015 a 2 de janeiro de 2016) foram, $27,53{ }^{\circ} \mathrm{C}$; $79,93 \%$ e $114,9 \mathrm{~mm}$, respectivamente (INMET, 2016).
$O$ delineamento experimental foi em bloco casualizados (DBC), com 10 tratamentos, 3 repetições e 10 plantas por parcelas, totalizando 300 mudas. Os tratamentos consistiram de: T1resíduo de soja + solo (1:2); T2- resíduo de soja + solo (1:3); T3- resíduo de soja + solo (1:4); T4resíduo de algodão + solo (1:2); T5- resíduo de algodão + solo (1:3); T6- resíduo de algodão + solo (1:4); T7- resíduo de cana-de-açúcar + solo (1:2); T8- resíduo de cana-de-açúcar + solo (1:3); T9- resíduo de cana-de-açúcar + solo (1:4); T10solo (testemunha).

Os resíduos vegetais utilizados para o preparo dos tratamentos foram obtidos em fazendas próximas à cidade de Nova Xavantina-MT. A composição química dos resíduos vegetais está apresentada na Tabela 1 e a análise química do solo utilizado na composição dos substratos está apresentada na Tabela 2.

Tabela 1. Composição química dos resíduos vegetais de soja, algodão e cana-de-açúcar utilizados na formulação dos substratos na produção de mudas de maracujazeiro em Nova Xavantina-MT.

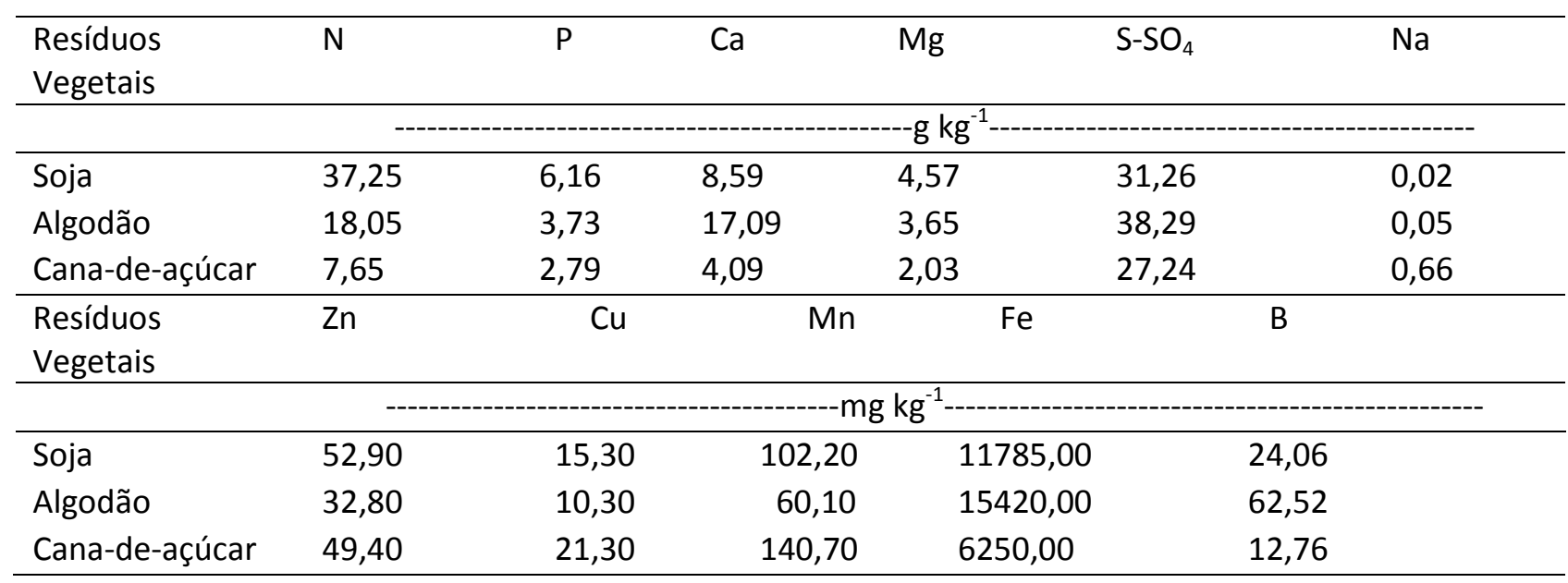


Tabela 2. Análise química do solo utilizado na formulação dos substratos na produção de mudas de maracujazeiro em Nova Xavantina-MT.

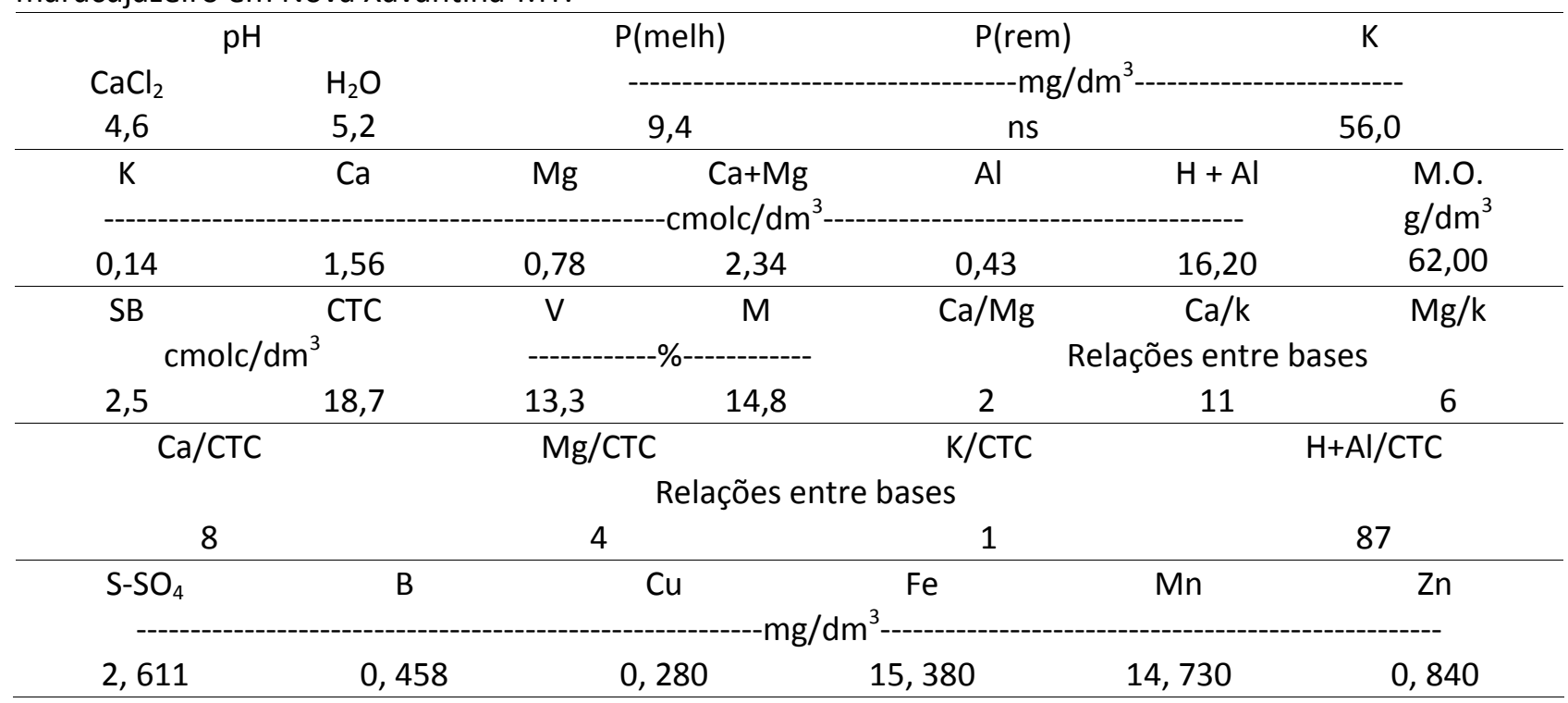

Foram semeadas três sementes de maracujazeiro-amarelo (Passiflora edulis Sims f. flavicarpa Deg.), cultivar 'FB200 Yellow Master', por saquinho de polietileno com capacidade para $1 \mathrm{dm}^{3}$ de substrato. Após a germinação das sementes e o desenvolvimento das plântulas, foi feito o desbaste deixando-se apenas a planta mais vigorosa por recipiente.

As mudas foram dispostas em bancadas de plástico, em viveiro telado com sombrite de $50 \%$ de luminosidade. Os tratos culturais realizados foram a irrigação, feita manualmente com auxílio de um regador, controle manual de pragas e plantas daninhas. Semanalmente foi mensurada a altura de plantas com o auxílio de fita métrica com o intuito de avaliar o crescimento das mudas ao longo do período de execução do trabalho e os dados foram expressos em centímetros.

Após 60 dias da semeadura foram avaliadas as seguintes características: altura de planta $(\mathrm{cm})$; diâmetro do caule $(\mathrm{mm})$ a $2 \mathrm{~cm}$ do colo da planta usando paquímetro digital; número de folhas por planta; massa fresca (g) e seca (g) da parte aérea e do sistema radicular.

As mudas foram retiradas dos saquinhos e as raízes lavadas em água corrente para retirada do solo aderido às raízes, em seguida separou-se a parte aérea das raízes com o auxílio de uma tesoura. As partes foram pesadas em balança semi-analítica para determinação da massa fresca. Posteriormente, as partes foram colocadas em sacos de papel e levadas para estufa a $65^{\circ} \mathrm{C}$ até atingirem peso constante. Em seguida foram efetuadas as pesagens, obtendose assim a massa seca de cada parte analisados pelo software Sisvar, ao nível de $5 \%$ de probabilidade, sendo as médias comparadas pelo teste Tukey.

\section{Resultados e Discussão}

O substrato formulado com resíduo de canade-açúcar + solo (1:2) foi o que proporcionou maior crescimento das mudas de maracujazeiro ao final do experimento (60 dias após a semeadura), apresentando maior altura $(63,03$ $\mathrm{cm})$, diâmetro do caule $(4,25 \mathrm{~mm})$ e número de folhas $(13,26)$ (Tabela 3$)$. O bagaço de cana-deaçúcar é um subproduto fibroso resultante da moagem da cana utilizado na formulação de substratos quando incorporado ao solo. 
Tabela 3. Altura, diâmetro do colo, número de folhas, massa fresca de parte aérea (MFPA), massa fresca de raiz (MFR), massa seca de parte aérea (MSPA) e massa seca de raiz (MSR) de mudas de maracujazeiro produzidas em substratos com diferentes resíduos vegetais.

\begin{tabular}{llllllll}
\hline \multicolumn{1}{c}{ Substratos } & $\begin{array}{c}\text { Altura } \\
(\mathrm{cm})\end{array}$ & $\begin{array}{c}\text { Diâmetro } \\
(\mathrm{mm})\end{array}$ & $\begin{array}{l}\text { Número } \\
\text { de folhas }\end{array}$ & $\begin{array}{c}\text { MFPA } \\
(\mathrm{g})\end{array}$ & $\begin{array}{c}\text { MFR } \\
(\mathrm{g})\end{array}$ & $\begin{array}{c}\text { MSPA } \\
(\mathrm{g})\end{array}$ & $\begin{array}{c}\text { MSR } \\
(\mathrm{g})\end{array}$ \\
\hline Soja + solo (1:2) & $30,97 \mathrm{bc}$ & $2,49 \mathrm{c}$ & $10,52 \mathrm{bc}$ & $14,51 \mathrm{bc}$ & $3,09 \mathrm{c}$ & $5,10 \mathrm{abc}$ & $0,55 \mathrm{bcd}$ \\
Soja + solo (1:3) & $44,30 \mathrm{abc}$ & $3,06 \mathrm{bc}$ & $11,69 \mathrm{abc}$ & $\begin{array}{l}21,65 \mathrm{ab} \\
4,80 \mathrm{bc}\end{array}$ & $\begin{array}{l}7,7 \mathrm{a} \\
0,34 \mathrm{~cd}\end{array}$ \\
Soja + solo (1:4) & $52,02 \mathrm{abc}$ & $3,31 \mathrm{abc}$ & $13,15 \mathrm{ab}$ & $17,48 \mathrm{abc}$ & $5,19 \mathrm{bc}$ & $4,60 \mathrm{bc}$ & $0,32 \mathrm{~cd}$ \\
Algodão + solo (1:2) & $56,86 \mathrm{ab}$ & $3,68 \mathrm{ab}$ & $10,10 \mathrm{c}$ & $20,29 \mathrm{ab}$ & $7,21 \mathrm{ab}$ & $4,08 \mathrm{bc}$ & $0,76 \mathrm{~b}$ \\
Algodão + solo (1:3) & $44,04 \mathrm{abc}$ & $3,30 \mathrm{abc}$ & $11,46 \mathrm{abc}$ & $16,33 \mathrm{abc}$ & $4,81 \mathrm{bc}$ & $6,97 \mathrm{ab}$ & $0,68 \mathrm{bc}$ \\
Algodão + solo (1:4) & $51,67 \mathrm{abc}$ & $3,54 \mathrm{ab}$ & $11,71 \mathrm{abc}$ & $18,01 \mathrm{abc}$ & $4,49 \mathrm{bc}$ & $3,70 \mathrm{c}$ & $0,43 \mathrm{bcd}$ \\
Cana-de-açúcar + solo (1:2) & $63,03 \mathrm{a}$ & $4,25 \mathrm{a}$ & $13,26 \mathrm{a}$ & $25,73 \mathrm{a}$ & $9,79 \mathrm{a}$ & $7,10 \mathrm{ab}$ & $1,63 \mathrm{a}$ \\
Cana-de-açúcar + solo (1:3) & $45,92 \mathrm{abc}$ & $3,51 \mathrm{ab}$ & $11,55 \mathrm{abc}$ & $18,65 \mathrm{abc}$ & $5,21 \mathrm{bc}$ & $4,94 \mathrm{abc}$ & $0,38 \mathrm{bcd}$ \\
Cana-de-açúcar + solo (1:4) & $33,30 \mathrm{bc}$ & $2,82 \mathrm{bc}$ & $10,73 \mathrm{abc}$ & $11,78 \mathrm{bc}$ & $3,87 \mathrm{bc}$ & $4,20 \mathrm{bc}$ & $0,32 \mathrm{bcd}$ \\
Solo & $30,43 \mathrm{c}$ & $2,46 \mathrm{c}$ & $10,18 \mathrm{c}$ & $8,48 \mathrm{c}$ & $2,35 \mathrm{c}$ & $2,11 \mathrm{c}$ & $0,19 \mathrm{~d}$ \\
\hline
\end{tabular}

* Médias seguida pelas mesmas letras não diferem estatisticamente entre si pelo teste de Tukey ao nível de $5 \%$ de probabilidade.

O maior crescimento em altura, diâmetro do caule e número de folhas no tratamento composto por cana-de-açúcar + solo (1:2) pode ser atribuído ao melhor equilíbrio químico e às boas condições físicas proporcionadas por este substrato, que possivelmente favoreceram a disponibilidade de água e nutrientes para as mudas. Klein (2015) caracterizou as propriedades físicas do bagaço de cana e concluiu que este substrato apresenta boa estabilidade de partícula, que é uma característica desejável em substratos para mudas e porosidade total considerada satisfatória (acima de $0,50 \mathrm{~m}^{3} \mathrm{~m}^{-3}$ ).

Serrano et al. (2006) trabalhando com substrato composto por resíduos da agroindústria canavieira para produção de mudas de maracujazeiro amarelo verificaram que 0 substrato composto pela mistura de bagaço de cana + torta de filtro e o substrato comercial, ambos fertilizados com adubo de liberação lenta, foram os que conferiram maior crescimento e melhor estado nutricional das mudas de maracujazeiro amarelo. Os resultados demonstram que este substrato é adequado para essa finalidade, pois conferiu às mudas qualidade semelhante ou superior quando comparado ao uso de outros substratos.

Os parâmetros altura da muda, diâmetro do caule, número de folhas por planta e massa seca da parte aérea têm grande importância como indicativo da qualidade da muda, pois refletem seu crescimento em função da quantidade de nutrientes absorvidos advindos do substrato (REIS et al., 2013).

Os substratos contendo apenas solo (testemunha) e resíduo de soja + solo (1:2), proporcionaram menor altura de planta $(30,43$ $\mathrm{cm}),(30,97 \mathrm{~cm})$, e menores diâmetros do caule, 2,46 e $2,49 \mathrm{~mm}$, respectivamente. Com relação ao número de folhas, a testemunha $(10,18$ folhas planta $^{-1}$ ) e o tratamento contendo resíduo de algodão + solo (1:2) (10,10 folhas planta $\left.{ }^{-1}\right)$ apresentaram os piores resultados. Deduz-se, portanto, que o substrato contendo apenas solo não foi eficiente para promover um satisfatório crescimento da muda de maracujazeiro, possivelmente, por não possuir características físicas e químicas adequadas para o bom desenvolvimento da muda.

Pode-se inferir por estes resultados, que o resíduo da soja por ser bastante concentrado em nitrogênio $\left(37,25 \mathrm{~g} \mathrm{~kg}^{-1}\right)$ (Tabela 1), quando utilizado em maiores proporções (1:2, resíduo:solo) resulta em menor crescimento de planta possivelmente por provocar fitotoxidez às mudas. O excesso de nitrogênio pode causar desequilíbrio nutricional na planta resultando em menor crescimento. Mendonça et al. (2004), testando diferentes doses de adubação nitrogenada e substratos no desenvolvimento de mudas de maracujazeiro amarelo, concluíram que doses até $2,0 \mathrm{~kg} \mathrm{~N} \mathrm{~m}^{-3}$ de substrato promovem maior qualidade das mudas, acima disso podem proporcionar efeitos negativos no crescimento das plantas.

O tratamento contendo resíduo de algodão + solo (1:2) pode ter apresentado menor número de folhas em função da maior concentração de $K$ presente no resíduo de algodão $\left(22,20 \mathrm{~g} \mathrm{~kg}^{-1}\right)$. Segundo Rodrigues (2012) os substratos formulados com resíduo da indústria têxtil, em função do elevado teor de potássio podem, 
eventualmente, proporcionar menor crescimento de mudas, pois este nutriente em excesso pode interferir na absorção de outros exercendo efeito competitivo com $\mathrm{Ca}$ e $\mathrm{Mg}$, uma vez que, durante o processo de absorção radicular, estes nutrientes utilizam os mesmos sítios carregadores (MALAVOLTA et al., 1997).

Verifica-se que o tratamento composto por resíduo de cana-de-açúcar + solo (1:2), apresentou melhor desempenho para massa fresca de parte aérea $(25,72 \mathrm{~g})$ e de raiz $(9,79 \mathrm{~g})$ e a massa seca de parte aérea $(7,10 \mathrm{~g})$ e de raiz $(1,63 \mathrm{~g})$ das mudas de maracujazeiro. Esse resultado possivelmente ocorreu em função das boas características proporcionadas por este composto.

O substrato composto apenas por solo (testemunha) apresentou valores mais baixos para as massas fresca e seca de parte aérea e raiz, possivelmente pela falta de adubação suplementar, sendo o fornecimento dos nutrientes presentes no solo (Tabela 2) insuficiente para o crescimento satisfatório da muda. Souza et al. (2015), avaliando diferentes resíduos vegetais na produção de mudas de alface em bandejas verificaram fitotoxidez do resíduo de soja, resultando em menor crescimento das mudas, consequentemente menor massa.

Figura 1. Crescimento de mudas de maracujazeiro produzidas em substratos com diferentes resíduos vegetais.

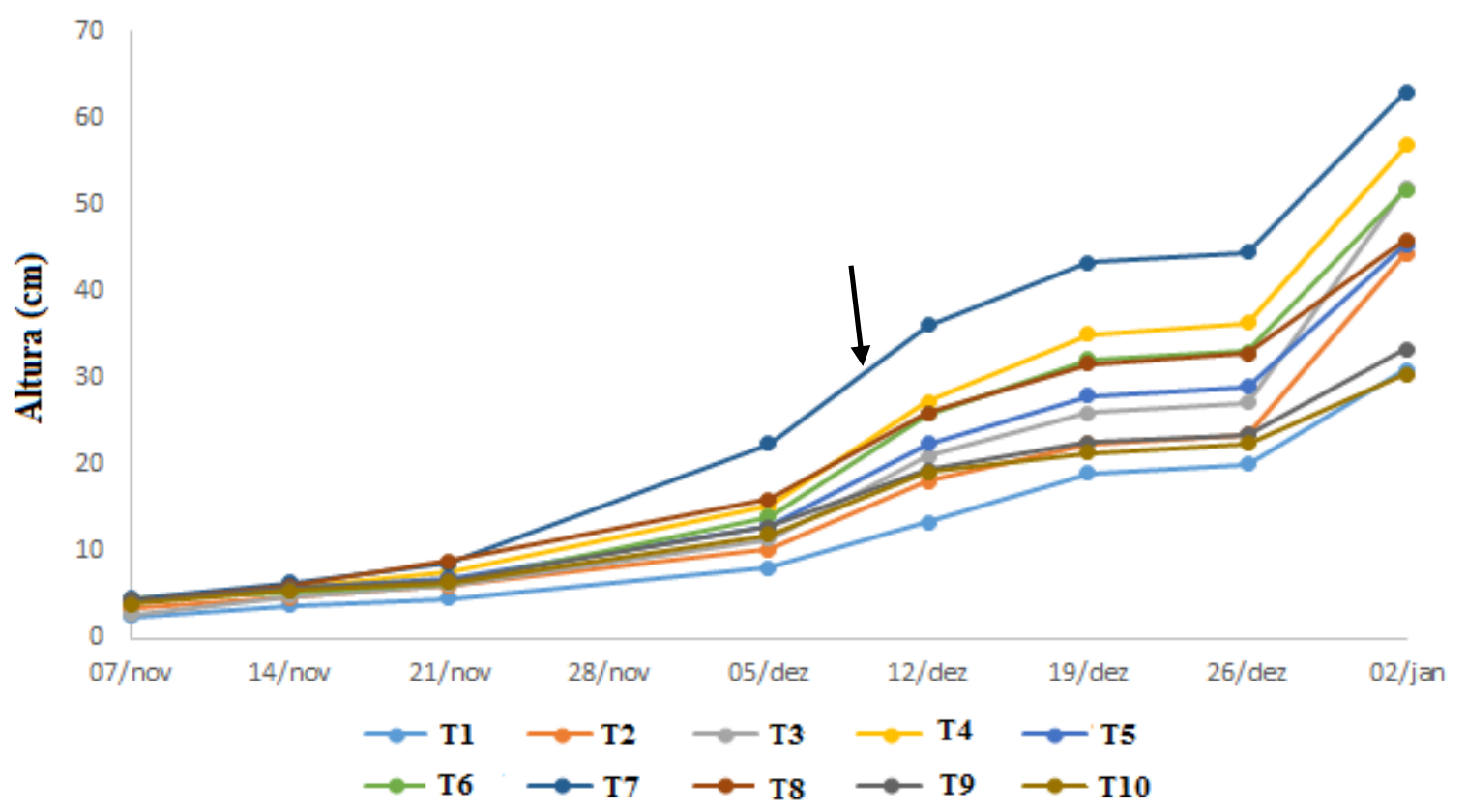

T1- Resíduo de Soja + Solo (1:2); T2- Resíduo de Soja + Solo (1:3); T3- Resíduo de Soja + Solo (1:4); T4Resíduo de Algodão + Solo (1:2); T5- Resíduo de Algodão + Solo (1:3); T6- Resíduo de Algodão + Solo (1:4); T7- Resíduo de Cana-de-Açúcar + Solo (1:2); T8- Resíduo de Cana-de-Açúcar + Solo (1:3); T9- Resíduo de Cana-de-Açúcar + Solo (1:4); T10- Solo (Testemunha).
A Figura 1 indica que o tratamento 7 (resíduo de cana de açúcar + solo (1:2)) apresentou maior crescimento ao longo das avaliações, atingindo a altura recomendada para o transplantio ao campo $(30 \mathrm{~cm})$ entre a quarta e quinta semana após a semeadura, portanto, antes dos demais tratamentos. Normalmente as mudas de maracujazeiro são transplantadas quando implantação de um pomar no qual se pretende conviver com possíveis viroses, recomenda-se que as mudas sejam transplantadas com altura de 0,8 a 1,5 cm (DAMATTO JUNIOR et al., 2014). A utilização de mudas de maracujazeiro-amarelo maiores $(1,5$ e $1,9 \mathrm{~m})$ proporcionam frutos maiores com melhor qualidade e maior produtividade em comparação com mudas de 0,3 m, 0,7 m e 1,10 m (RIBEIRO et al., 2012). Santos et al. (2014) estudando diferentes idades de mudas $(25,50,75,100$ e 125 dias, após emergência) na produção e qualidade do maracujazeiro amarelo verificaram que mudas de menor idade obtiveram baixa produtividade, frutos menores e com menor rendimento de suco, enquanto a utilização de mudas com idades de 100 e 125 dias após emergência apresentou resultados satisfatórios para todas as características avaliadas. atingem cerca de $30 \mathrm{~cm}$ de altura, porém, para a 
O tratamento T1 (resíduo de soja + solo (1:2)), apresentou menor crescimento em altura, seguido pelo tratamento T10 (testemunha); o primeiro, possivelmente em função do efeito fitotóxico do resíduo de soja e o segundo, pela quantidade limitada de nutrientes, promovendo crescimento mais lento da planta (Tabela 1 e 2). As mudas destes tratamentos apenas atingiram a altura de $30 \mathrm{~cm}$ na oitava semana após a semeadura. Cabe ressaltar que quanto menor o período para obtenção da muda, mais rápido será o retorno econômico do viveirista/produtor.

Apesar da superioridade do tratamento composto por resíduo de cana-de-açúcar + solo (1:2), é importante salientar que todos os substratos utilizados neste trabalho atingiram a altura $(30 \mathrm{~cm})$ indicada para plantio em campo ao final do experimento. Assim, qualquer um dos resíduos vegetais testados, cana-de-açúcar, algodão e soja, poderiam ser recomendados para a produção de mudas de maracujazeiro, em substituição ao substrato composto apenas por solo (testemunha). Dessa forma, na indisponibilidade do resíduo de cana-de-açúcar, pode-se alternativamente recomendar o uso do resíduo de algodão ou soja para a produção de mudas de maracujazeiro em proporções adequadas.

\section{Conclusão}

O substrato contendo resíduo de cana-deaçúcar + solo na proporção de 1:2 proporcionou maior crescimento de mudas de maracujazeiro amarelo.

\section{Referências}

ALMEIDA, M.O.; CRUZ, M.C.M.; CASTRO, G.D.M.; FAGUNDES, M.C.P. Crescimento e absorção de nutrientes por mudas de maracujazeiro-amarelo em substratos orgânico e comercial e adubação nitrogenada. Revista Brasileira de Ciências Agrárias, v.9, n.2, p.180-185, 2014. https://doi.org/10.5039/agraria.v9i2a3593

ANUÁRIO BRASILEIRO DE FRUTICULTURA 2015. Santa Cruz do Sul: Editora Gazeta, p. 06, 2015.

CALDEIRA, M.V.W.; BLUM, H.; BALBINOT, R.; LOMBARDI, K.C. Uso do resíduo de algodão no substrato para produção de mudas florestais. Revista Acadêmica: Ciências Agrárias e Ambientais, v. 6, n. 2, p. 191-202, 2008.
COSTA, C.A.; RAMOS, S.J.; SAMPAIO, R.A.; GUILHERME, D.O.; FERNANDES, L.A. Fibra de coco e resíduo de algodão para substrato de mudas de tomateiro. Horticultura Brasileira, v. 25, n. 3, p. 387-391, 2007. https://doi.org/10.1590/S0102$\underline{05362007000300013}$

DAMATTO JUNIOR, E.R.; FUZITANI, E.J.; NOMURA, E.S. Produção de mudas de maracujá com uso de mudas avançadas no vale do Ribeira. APTA Pesquisa e tecnologia, v. 11, n. 1, 2014.

INSTITUTO NACIONAL DE METEOROLOGIA. Banco de dados meteorológicos (BDMEP) para ensino e pesquisa. Disponível em: http://www.inmet.gov.br/portal/index.php?r=bd mep/bdmep. Acesso em: 09 Junho 2016.

KLEIN, C. Utilização de substratos alternativos para produção de mudas. Revista Brasileira de Energias Renováveis, v.4, p. 43-63, 2015. https://doi.org/10.5380/rber.v4i3.40742

MALAVOLTA, E.; VITTI, G.C.; OLIVEIRA, S.A. Avaliação do estado nutricional das plantas: princípios e aplicações. Piracicaba, p. 201, 1997.

MENDONÇA, V; ABREU, A.A.; TEIXEIRA, G.A.; SOUZA, H.A.; GURGEL, R.L.S.; FERREIRA, E.A.; RAMOS, J.D. Adubação nitrogenada e diferentes substratos no desenvolvimento de mudas de maracujazeiro amarelo. XIII Congresso dos PósGraduandos da UFLA, Lavras, 2004.

MELETTI, L.M.M. Avanços na cultura do maracujá no Brasil. Revista Brasileira Fruticultura, v. E, p. 87-91, 2011.

RAMOS, J.D.; CHALFUN, N.N.J.; PASQUAL, M.; RUFINI, J.C.M. Produção de mudas de plantas frutíferas por semente. Informe Agropecuário, v. 23, n. 216, p. 64-72, 2002.

REIS, J.M.R.; RODRIGUES, J.F.; REIS, M.A. Produção de mudas de maracujazeiro amarelo com diferentes substratos. Enciclopédia Biosfera, Centro Científico Conhecer, v.10, n.18; p. 2024, 2013.

RIBEIRO, M.I.G; SANTOS, V.A.; RAMOS, J. D.; CHAGAS, E. A.; LAREDO, R. R.; SOUZA, A. G. Tamanho da muda na produtividade e qualidade dos frutos de maracujazeiro-amarelo. In: XXII 
Congresso Brasileiro de Fruticultura, 2012, Bento Gonçalves, Anais... CD-ROM.

RODRIGUES, A.L. Utilização de substratos orgânicos e comercial na produção de mudas de maracujazeiro azedo cv. Redondo. Conclusão de Curso (Agronomia) Universidade Federal dos Vales do Jequitinhonha e Mucuri, Diamantina, 2012.

SANTOS, V.A.; RAMOS, J.D.; LAREDO, R.R.; SILVA, F.O.R.; CHAGAS, E.A.; PASQUAL, M. Produção e qualidade de frutos de maracujazeiro-amarelo provenientes do cultivo com mudas em diferentes idades. Revista de Ciências Agroveterinárias, Lages, v. 16, n. 1, 2017.

SERRANO, L.A.L.; SILVA, C.M.M. OGLIARI, J.; CARVALHO, J.C.; MARINHO, C.S.; DETMANN, E. Utilização de substrato composto por resíduos da agroindústria canavieira para produção de mudas de maracujazeiro-amarelo. Revista Brasileira de Fruticultura, v.28, n.3, p. 487-491, 2006. https://doi.org/10.1590/S0100$\underline{29452006000300032}$

SILVA, R.F.; EITELWEIN, M.T.; CHERUBIN, M.R.; FABBRIS, C.; WEIRICH, S.; PINHEIRO, R.R. Produção de mudas de eucalyptus grandis em substratos orgânicos alternativos. Ciência Florestal, v. 24, n. 3, p. 609-619, 2014. https://doi.org/10.5902/1980509815745

SOARES,' L.S.; MORIS, V. A. S.; YAMAJI, F.M.; PAIVA, J.M.F. Utilização de Resíduos de Borra de Café e Serragem na Moldagem de Briquetes e Avaliação de Propriedades. Matéria (Rio de Janeiro), v. 20, n .2, p.550-560, 2015.

SOUZA, C.J.; USHIWATA, S.Y.; REIS, R.G. E.; VILAR, C.C.; MASSOLA, M.P.; SOUZA, M.E. Desempenho de plântulas de alface cultivada em diferentes substratos orgânicos. Anais Semana CientíficaUNEMAT, Caderno de Publicações, v.3, n.1, p.25, 2015.

TORRES, G.A.; TARIFA, L.R.M. Aproveitamento de Resíduos Agrícolas. Dossiê técnico 2012. Serviço Brasileiro de Respostas Técnicas - SBRT. Universidade de São Paulo - USP, 2012. 